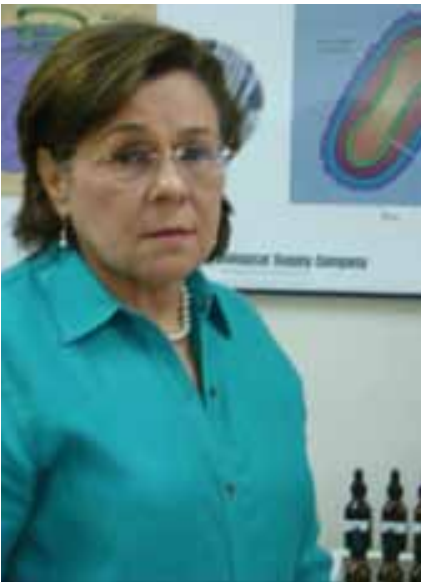

鼔

\title{
PASOS Y HUELLAS
}

\section{Entrevista a la profesora Rosario Granados}

Cuaderno de Pedagogía Universitaria entrevista a la Dra. Rosario Granados, Profesora Titular del Departamento de Ciencias Básicas, una persona de larga y reconocida trayectoria en la docencia de Biología en nuestra Universidad. La entrevista gira en torno a las estrategias de enseñanzaaprendizaje en su práctica docente.

1. Usted es profesora del Departamento de Ciencias Básicas. ¿Desde qué año imparte docencia y con cuáles asignaturas ha estado vinculada? Formo parte del cuerpo docente de la PUCMM desde 1968, siempre vinculada al área de Biología. He impartido, tanto la teoría como los laboratorios, de las asignaturas de Biología General, Biología 1, Biología 2, Biología Celular y Genética, Zoología de Vertebrados y de Invertebrados, Preparaciones Biológicas, Enseñanza de la Biología para Nivel Básico y Medio. Actualmente, tengo un contrato especial puesto que aunque soy beneficiaria de la jubilación, me mantengo activa y entusiasmada con la docencia. Por lo general, imparto 15 créditos, que es lo estipulado para un profesor a Tiempo Completo.

2. ¿Cuáles son las características del estudiantado que recibe? ¿Han variado estas a través de los años?

Los estudiantes cambian, van evolucionando como consecuencia del momento histórico que les toca vivir. En efecto, los estudiantes de hace 40 años distan de parecerse a los de ahora. El estudiante de hoy está poco motivado, presenta pocas inquietudes intelectuales y es un usuario muy activo de la tecnología, casi dependiente. Con esto último no quiero decir que sea incorrecta dicha dependencia, sino que es preciso preguntarse sobre la forma en que está siendo manejada, para poder utilizarla de aliada y que ayude al desarrollo profesional e intelectual. Hasta hace unos 15 años, el estudiante venía más definido en su vocación, se percibía que tenía unas metas claras, se involucraba en más lecturas y podía exhibir una mayor vida intelectual.

3. ¿Qué características tendría el estudiantado ideal que usted pretende formar a través de su docencia?

Creo en formar personas con la "impronta" de la PUCMM. Para mí, esto significa madurez humana, con esto quiero decir, ubicados en su familia, en su edad y en su sociedad; además, con inquietudes sociales y con un desarrollo intelectual y reflexivo a la altura de los tiempos modernos. Esto le permitirá insertarse en la sociedad como entes productivos y responsables con las capacidades y actitudes necesarias para enfrentar los grandes retos del milenio.

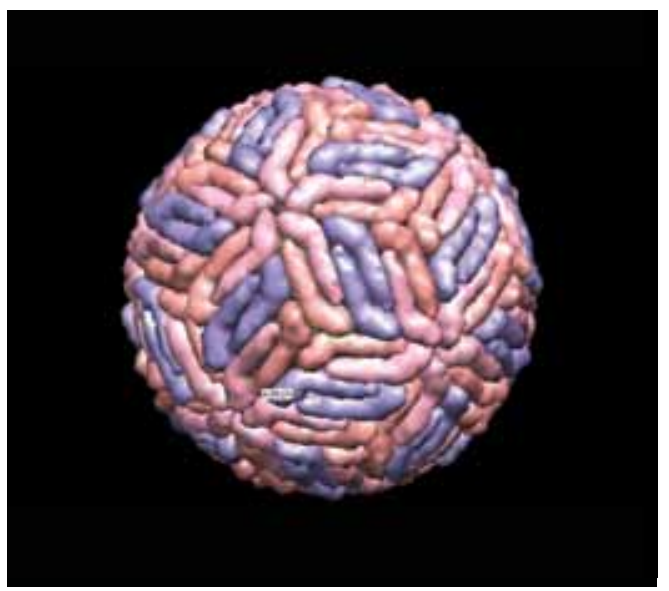

Foto 1 - Estructura molecular de la capside del virus del Dengue

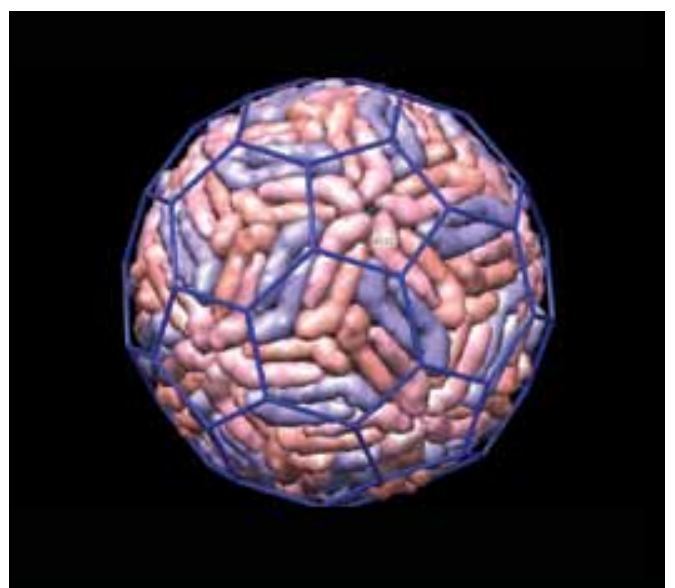

Foto 2 - Conformación geométrica

Encuentre el texto en "Estrategias de enseñanza-aprendizaje" http://www.pucmm.edu.do/STI/campus/CDP/ComunicaciónPublicaciones/Paginas/CuadernodePedagogiaUniversitaria.aspx

Cuaderno de Pedagogía Universitaria Año 8/ N. 15 /enero - junio 2011 / Santiago, Rep. Dom.: PUCMM / pp.36-38 
4. Si usted reflexionara con respecto a su metodología docente, es decir, la manera en que usted ayuda a sus estudiantes a aprender, ¿cuáles son los conceptos de enseñanza-aprendizaje que están detrás de su práctica?

El primer concepto que aplico es respeto al alumno, posteriormente trabajo insistentemente para despertar su motivación. Intento ubicar a los alumnos en la Universidad, es decir, que conozcan y vivan su filosofía al igual que la asignatura. Siempre busco que sean reflexivos y críticos, que puedan establecer al final de la materia cómo construyeron sus conocimientos, con qué llegaron y con qué se van a nivel de aprendizaje.

5. ¿Cómo ha evolucionado su docencia en el curso del tiempo, a qué causas lo atribuye y de qué estrategias y/o recursos didácticos se ha valido?

Mi docencia ha evolucionado en función de cómo ha evolucionado científicamente la disciplina. Cuando me inicié en la Biología, esta se estudiaba a nivel de organismos. Ahora visualizamos la Biología a nivel molecular y nos auxiliamos de las demás ciencias básicas, así como de la tecnología. Ahora es posible analizar la expresión simultánea de miles de genes mediante el uso de la tecnología de micromatrices de ADN. Los contenidos de la asignatura son más abstractos, por lo que se hace preciso enseñarlos de otra forma. En consecuencia, podría decir que mi clase ha evolucionado con respecto a dos aspectos: a) el uso de la tecnología para fines didácticos y b) el uso de los conocimientos que aportan otras disciplinas científicas.

En cuanto al uso de la tecnología para fines didácticos, estoy asociada a varias entidades internacionales para formación y actualización. Dos de ellas son el Massachusetts Institute of Technology (MIT) y Saint Louis University y otras dos son la Nacional Scientific Teaching Association (NSTA) y la Sigma Xi, The Scientific Research Society, por citar algunas. Gracias a esto, recibo gran cantidad de información, con énfasis en la utilización de la tecnología para la docencia.
Por ejemplo, en las Fotos 1-5 aparecen distintas perspectivas de visualización de un modelo científico en 3D del virus del Dengue. La versatilidad y la rapidez con que se pueden asociar conceptos a través de las imágenes es mayor ahora que en épocas previas de docencia. Es vital, sin embargo, no perder de vista que la tecnología es solo un recurso, que nos ha permitido conectar los conocimientos antes disgregados. Por eso, debemos usarla correctamente para que pueda motivar al estudiante y profundizar su conocimiento.

Otro ejemplo es la ayuda de la tecnología para las clases del laboratorio. A partir de manuales elaborados en el Departamento, los estudiantes primero leen y se documentan sobre cómo proceder en el laboratorio. Una vez hecho esto, ellos elaboran un plan de trabajo por grupos y cuando llegan a la parte experimental preparan por sí mismos todo lo que necesitan. Yo intervengo para observar y contestar las preguntas. Tenemos una gran ventaja con la tecnología, pues para estudiar algo tan sencillo como una ameba, primero manipulan la ameba virtualmente y luego la observan con el microscopio. Es decir, aprenden haciendo. En la Foto 6 aparece un ejemplo de esta idea (una electromicrofotografia de una célula hepática) la lupa se mueve para agrandar, virtualmente y a color, lo que se quiere ver.

En cuanto al otro aspecto mencionado, el uso de los conocimientos que aportan otras disciplinas, es algo ineludible en la Biología, y más hoy en día. La Biología es la ciencia que estudia los seres vivos, y en el universo hay dos componentes: materia y energía. Por eso, la Biología no es posible sin Matemáticas, Física y Química. Las ciencias básicas son interdisciplinarias. En mi clase me aprovecho de los conocimientos que traen los estudiantes desde las otras ciencias.

En este sentido, me gustaría destacar la importancia que tiene la enseñanza de las ciencias en nuestra Universidad. En coherencia con el lema de "Verdad y Ciencia", la PUCMM asume un compromiso con la oferta académica científica. Es importante que los estudiantes de cualquier carrera tengan una formación en las ciencias

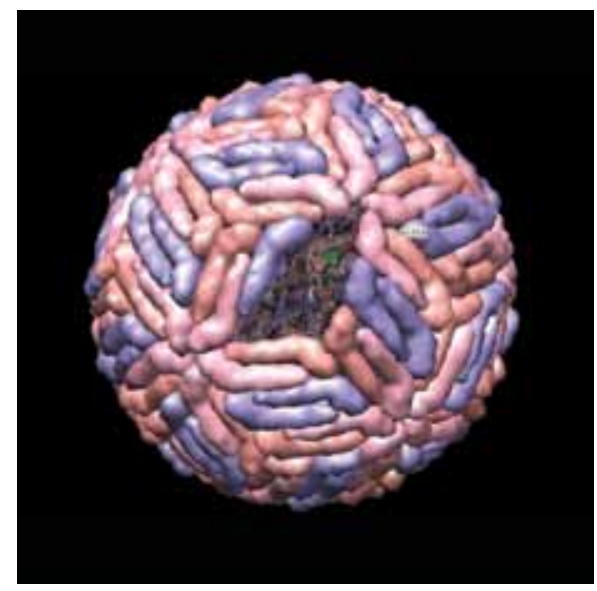

Foto 3 - Representación del enrollamiento de una molécula de proteína

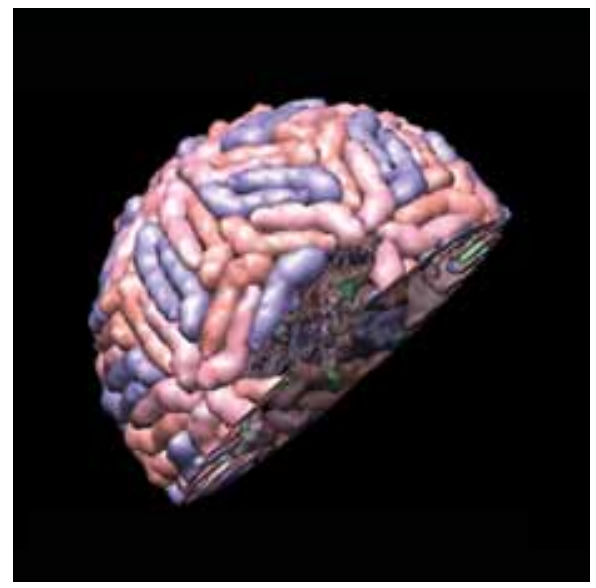

Foto 4 - Corte transversal del virus

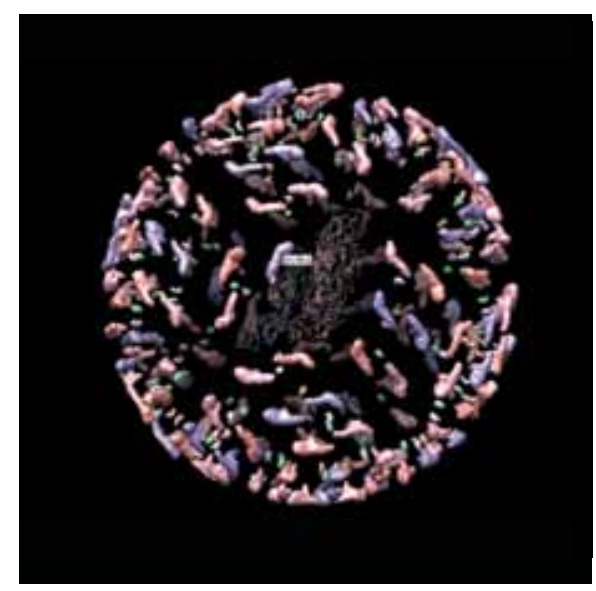

Foto 5 - Desintegración de los enlaces covalentes de las proteínas

Entrevista a la profesora Rosario Granados

Cuaderno de Pedagogía Universitaria Año 8/ N. 15 / enero - junio 2011 / Santiago, Rep. Dom.: PUCMM / pp.36-38 
básicas que no debería ser nunca soslayada frente a los cambios en los requerimientos curriculares.

6. ¿Las variaciones que usted relata en las estrategias y/o en los recursos han sido introducidas por su cuenta o han surgido de procesos organizados de revisión curricular?

Ambas realidades han tenido su influencia, los programas han ido evolucionando con los tiempos en función de los descubrimientos y avances científicos de esta disciplina. Pero también, realizo una revisión constante de las estrategias, el orden y profundidad de los contenidos, siempre trato de innovar, incorporando todos los mecanismos viables, tanto en las clases de teoría como en los laboratorios. Como he mencionado anteriormente, trato de mantenerme al día, aprovechando al máximo las grandes facilidades a las que se pueden acceder a través de la red.

Finalmente, podría decir, mirando hacia atrás y observando con detenimiento el camino recorrido, que la experiencia ha valido la pena. Ser un docente universitario involucra reinventarse cada semestre, exige el planteamiento constante de nuevas metas, mantiene la esperanza, ya que siempre estamos rodeados de jóvenes, pues aunque cambien los tiempos y las formas, ellos siempre sueñan con un mundo mejor.

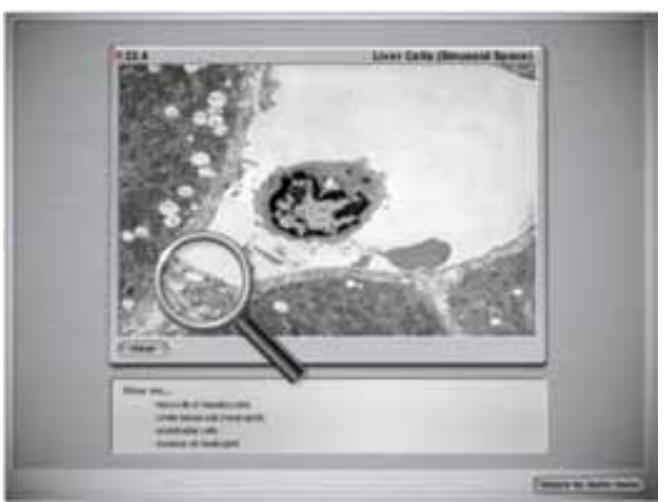

Foto 6 - Un ejemplo de manipulación virtual en actividades propias de una asignatura de laboratorio.
Como apéndice a esta entrevista, el equipo editorial del Cuaderno de Pedagogía Universitaria solicitó a dos ex alumnos de la profesora Granados algunos comentarios acerca de la experiencia de haberla tenido como docente. A continuación, lo que ellos enviaron:

La primera clase que tomé en la universidad fue con la Dra. Granados. Recuerdo que todos estábamos algo nerviosos y desubicados. Sin embargo, no habían pasado 10 minutos cuando ya la doctora nos había hecho sentir más cómodos y relajados, ni siquiera nos dimos cuenta de cuándo comenzó la clase. El material era mucho y pesado, especialmente para quienes nos encontrábamos por primera vez tratando temas científicos de una manera tan profunda, pero los temas iban y venían con increíble fluidez gracias a que nuestra profesora tomaba las partes mas difíciles y las simplificaba con ejemplos prácticos de la vida diaria (como comparando una enzima y su receptor con una llave y su cerradura).

Lo que siempre llevaré conmigo de mi experiencia como estudiante suya es que nos alentaba a ser críticos sobre el material que leíamos, incluso sobre su propia cátedra. Nos ayudaba a que generáramos preguntas en base a lo que íbamos aprendiendo para que no nos quedáramos con lo que decía el libro de texto, sino que viéramos mas allá de lo publicado, que siguiéramos las investigaciones y estuviéramos atentos a los nuevos descubrimientos. Con ella aprendí que el conocimiento no es estático y que para descubrir algo, primero hay que ser curioso y hacerse las preguntas adecuadas, las que dan una respuesta distinta a lo que ya se conoce.

\section{Lilibette Alvino, estudiante de término de Medicina}

Para hablar de la Dra. Granados es de suma importancia recalcar que es una profesional que exige, puesto que de la misma manera o quizás en mayor magnitud, devuelve. El excelente desempeño que demuestran sus estudiantes desde el primer día de clases hasta el último día de cada ciclo, son muestras palpables de su habilidad como facilitadora de conocimientos.

Por otro lado, no está de más decir: el amor, el respeto y la responsabilidad que demuestra a la hora de impartir docencia. Todo lo mencionado previamente crea en nosotros un compromiso docente-estudiante, y he aquí donde está su sello; el sello que la diferencia de otros, que motiva al estudiante a tener una responsabilidad de agradecimiento para con ella, así pues, quien da debe recibir. Para culminar, cito una frase de Cicerón que es más que perfecta para describirla como docente: "Una cosa es saber, y otra, saber enseñar".

\section{Harold Cedeño, estudiante de término de Medicina}

